\title{
BMJ Open Factors influencing the willingness of primary care physicians to provide care during the coronavirus disease pandemic: a nationwide survey in Taiwan
}

Hsien-Liang Huang (D) ,1,2 Chyi-Feng Jeff Jan (D) , ${ }^{1,2}$ Brian Bih-Jeng Chang, ${ }^{1,3,4}$ Tai-Yuan Chiu (1) 1,2,4

To cite: Huang $\mathrm{H}-\mathrm{L}$, Jan CFJ, Bih-Jeng Chang B, et al. Factors influencing the willingness of primary care physicians to provide care during the coronavirus disease pandemic: a nationwide survey in Taiwan. BMJ Open 2021;11:e049148. doi:10.1136/ bmjopen-2021-049148

- Prepublication history and additional supplemental material for this paper are available online. To view these files, please visit the journal online (http://dx.doi.org/10.1136/ bmjopen-2021-049148).

Received 19 January 2021 Accepted 16 June 2021

Check for updates

(c) Author(s) (or their employer(s)) 2021. Re-use permitted under CC BY-NC. No commercial re-use. See rights and permissions. Published by BMJ.

${ }^{1}$ Department of Family Medicine, National Taiwan University Hospital, Taipei, Taiwan

${ }^{2}$ Department of Family Medicine, College of Medicine, National

Taiwan University, Taipei, Taiwan

${ }^{3}$ Brian's Family Doctor Clinic,

New Taipei City, Taiwan

${ }^{4}$ Taiwan Medical Association, Taipei, Taiwan

Correspondence to

Tai-Yuan Chiu;

tychiu@ntuh.gov.tw

\section{ABSTRACT}

Objectives The COVID-19 pandemic continues to advance worldwide with tremendous impact on public health, economy and society. Primary healthcare is crucial in every country during the pandemic for an integrated and coordinated healthcare delivery system; hence, it is of paramount importance to maintain a sufficient frontline workforce. This study aimed to identify factors influencing the willingness of primary care physicians to provide care during the COVID-19 pandemic.

Design Cross sectional study.

Setting Nationwide survey

Participants Primary care physicians working in the community in Taiwan were selected using a cluster sampling method based on practice region from May to June 2020.

Outcome measures The willingness of primary care physicians to provide care during the COVID-19 pandemic. Results This study surveyed 1000 primary care physicians nationwide, and 625 valid questionnaires were received and included in the final analysis, with an effective response rate of $62.5 \%$. Factors significantly associated with physicians willingness to provide care during COVID-19 were 'joining the Community Healthcare Group (CHCG)' $(p<0.001)$, 'perceived more overall benefits for providing care' $(p<0.001)$ 'perceived less overall barriers to providing care' $(p<0.001)$, 'higher knowledge scores about COVID-19' $(p=0.049)$ and 'physician's major specialties' $(p=0.009)$ in the multivariate logistic regression model.

Conclusions Building a comprehensive primary care system such as Taiwan's CHCG, training of more family physicians or general practitioners, and protecting and supporting primary care physicians were important in response to infectious disease pandemics. The findings of this study inform the development of guidelines to support and maintain the primary healthcare workforces during the COVID-19 pandemic and for future events.

\section{INTRODUCTION}

The COVID-19 pandemic continues to advance worldwide with tremendous impact on public health, economy and society.
Strengths and limitations of this study

- The study participants included primary care physicians in Taiwan, including different specialties and practice regions, selected using a nationwide cluster sampling method.

- The survey period was during the COVID-19 pandemic; the finding could be applied to the current COVID-19 pandemic situation as the unprecedented COVID-19 threats persisted.

- Taiwan implemented proactive strategies early in the pandemic to manage the crisis, and the effective response of the healthcare system may be informative to the world.

- The response rate was only moderate, and the results may not be generalisable to other countries with different healthcare system and government control strategies.

Moreover, the pandemic continues to progress with flare-ups in several countries. ${ }^{12}$ More than 143 million COVID-19 cases caused by SARS-CoV-2 were confirmed with more than 3 million deaths reported globally at the time of writing on 17 April 2021 by the WHO. ${ }^{3}$ While measures of infection control are gradually being relaxed, longitudinal and prolonged preparedness is necessary for the catastrophic possibility of resurgence in the coming years. 145

The primary healthcare system response to the COVID-19 outbreak as the first level of contact is crucial, and is assigned a key role on the frontline in every country facing undifferentiated cases. Different functions, designated for general practice, such as screening, education and home quarantine monitoring worldwide, are essential. Through integrated and coordinated healthcare delivery systems, primary care physicians could triage patients 
to specialised hospitals for proper care, to reduce overcrowding in the hospitals. Furthermore, at the primary healthcare system level, previous healthcare needs, such as chronic disease management, health promotion or initial acute non-infectious disease consultation, need to be maintained even when the system is besieged with consultation and testing needs for COVID-19 through walk-in clinics or telemedicine, worldwide. ${ }^{6-8}$ Along with hospital specialists, primary care physicians have a professional commitment to ensure the appropriate care of their patients while in hospital. ${ }^{9} 10$ Taiwan implemented proactive strategies early in the pandemic to manage the crisis, and the effective response of the healthcare system may be informative to the world. ${ }^{11} 12$ The Family Practice Integrated Care Project (FPICP) and Community Healthcare Group (CHCG) were established in Taiwan after the previous SARS epidemic. The FPICP emphasises the need for coordinated care between clinics and hospitals, and also provides continuous person-centred care for the patients. The FPICP establishes community care networks nationwide, with the basic unit of 5-10 clinics forming a CHCG team. Primary care physicians in the CHCG need to collaborate with each other and with those in the backup hospitals. These emphasise continuous, coordinated and comprehensive care for patients, and could be a suitable primary healthcare infrastructure to combat the COVID-19 pandemic. ${ }^{13} 14$ It is of paramount importance to maintain adequate medical care capacity during the pandemic, and research regarding the influence of innovative primary healthcare models, such as FPICP and CHCG, on the control of the pandemic is essential.

As the unprecedented pandemic threat persists over a broad range of medical care, it is of paramount importance to understand and optimise the primary healthcare workforce, and to maintain sufficient frontline physicians. ${ }^{15-18}$ However, previous reports revealed a high susceptibility to infection among healthcare workers because more than 3000 healthcare workers have been infected in China and 20\% of responding healthcare workers were infected early in the COVID-19 pandemic in Italy ${ }^{19}{ }^{20}$ Moreover, a systematic review by Kisely $e t a l^{21}$ revealed that healthcare workers who had direct contact with patients had higher levels of both acute and posttraumatic stress and psychological distress. In addition, workforce problems might be exacerbated by the refusal to work due to psychological factors and concern over their families. ${ }^{22} 23$ Up to $24 \%$ physicians and $26 \%$ nurses agreed to abandon their workplaces during a pandemic in a Germany survey during the H5N1 influenza outbreak, and absenteeism was as high as $85 \%$ during an influenza pandemic reported in a survey conducted in the UK. ${ }^{24}$ One study conducted in psychiatric hospitals at the peak of the COVID-19 pandemic revealed that about $23 \%$ of medical staff were unwilling to care for psychiatric patients with COVID-19. ${ }^{26}$ Therefore, attitudes of healthcare workers towards COVID-19 occurrences, such as perceived threats, benefits or barriers, might influence the provision of care to COVID-19 patients.
In confronting COVID-19, there is an urgent need to analyse individual, environmental and social factors that influence the willingness to provide healthcare during the pandemic. This nationwide survey aimed to identify the factors influencing the willingness of primary care physicians to provide care in their communities during the COVID-19 pandemic. The findings of this study will inform the development of guidelines to support and maintain the primary healthcare workforces during the COVID-19 pandemic and for future events.

\section{METHODS}

Design

This cross-sectional survey was conducted from May to June 2020 during the COVID-19 pandemic. The Medical Policy Committee of Taiwan Medical Association approved the study protocol.

\section{Participants}

The targeted participants were primary care physicians working in the community. Eligible respondents were recruited nationwide from the Taiwan Medical Association. The sample population comprised 1000 physicians in total.

\section{Recruitment}

A structured questionnaire was mailed to the targeted primary care physicians selected using a nationwide cluster sampling method. The clusters were identified according to the 22 counties and cities in Taiwan. The targeted primary care physicians were selected randomly by computer programme. One month after the questionnaire was mailed, non-respondents were contacted again, and the questionnaire survey was resent. The return of the questionnaire represented consent to participate in the survey.

\section{Measurements}

The structured self-reported questionnaire consists of six parts including questions on demographic characteristics; knowledge of COVID-19; attitude towards providing care during COVID-19 including threats, benefits and barriers related to the provision of care during COVID-19 as well as the global rating of benefits and barriers to care during COVID-19 and the willingness to provide care. The entire six part questionnaire was tested for face and content validity by a panel comprised of five primary care physicians and two infection specialists. The physicians filled out the questionnaire to confirm its face validity and ease of application. Each item in the questionnaire was appraised from 'very inappropriate and not relevant ${ }^{\text {' }}$ to "very appropriate and relevant'. ${ }^{5}$ A 'content validity index' (CVI) was used to determine the validity of the structured questionnaire, and the items were highly relevant if CVI higher than $0.8 .{ }^{27} 28$ The questionnaire yielded a CVI of 0.94 on all items (the knowledge and attitude 
questionnaire was provided as online supplemental file 1).

Demographic characteristics assessed by the questionnaire included age, gender, religion, specialty and information on current working conditions. The other questionnaire parts are described as follows:

1. Knowledge of COVID-19: this measure is about the practical knowledge of COVID-19 consisted of three main parts epidemiology (three items), diagnosis (nine items), personal protective equipment and management (eight items). The 20-item measure was designed by with careful scrutiny of the literature available in the beginning of the epidemic. This scoring system of this scale is 'true' (1) and 'false/unknown' (0). The internal consistency of this knowledge measure was assessed using Cronbach' s alpha, which showed a coefficient of 0.5-0.6.

2. Attitude towards providing care for COVID-19 patients: this measure included the perception of threats, benefits and barriers to providing care during COVID-19. This 21-item measure is assessed using a 5-point Likert scale, scored from 'strongly disagree' (1) to 'strongly agree' (5) and 'not important' (1) to 'very important' (5). Bartlett's test of sphericity and the Kaiser-Meyer-Olkin test were used to determine whether the attitude data were suitable for exploratory factor analysis. Therefore, the items were analysed using principal component factor analysis followed by orthogonal varimax rotation. The content was constructed using threats (seven items), benefits (seven items) and barriers to providing care for COVID-19 patients (seven items). Internal consistency was demonstrated with Cronbach's alpha coefficient ranging from 0.89 to 0.96 in the attitude subscale. Two global rating items: 'overall perceived benefits for providing care during COVID-19' and 'overall perceived barriers for providing care during COVID-19' used a 10-point Likert scale.

3. Willingness: this measure was used to determine the primary care physician's willingness (yes or no) to provide care during the COVID-19 pandemic.

\section{Statistical analysis}

Data management and statistical analyses were performed using SPSS Statistics for Windows V.10.0. Demographic data and distribution of each variable were described using frequency distribution. Mean values and SDs were used to analyse the degree, importance and necessity of 'knowledge about COVID-19' and 'attitude towards providing care during COVID-19' variable. The attitude variables in the model were global ratings of 'overall perceived benefits for providing care during COVID-19' and 'overall perceived barriers for providing care during COVID-19'. A univariate comparison including Student's t-test and $\chi^{2}$ test were carried out to determine differences in the variables related to willingness or unwillingness to provide care. Statistical significance was set at $\mathrm{p}<0.05$. Stepwise logistic regression analysis was carried out to determine the relative values of the variables in the model where the willingness to provide care was the dependent variable. To avoid collineation of the variables, 'overall perceived benefits for providing care during COVID-19' and 'overall perceived barriers for providing care during COVID-19', the two variables were analysed in two different models, respectively.

\section{Patient and public involvement}

As the research aimed on professional perspectives, primary care physicians were involved in the development and amendment of the questionnaire.

\section{RESULTS}

\section{Demographic characteristics}

A total of 625 valid questionnaires were returned and included in the final analysis after removing incomplete questionnaires by the surveyed physicians, with an effective response rate of $62.5 \%$.

As shown in table 1 , the 625 respondents had a mean age of $56.6 \pm 10.6($ mean $\pm \mathrm{SD})$ years, and most respondents were male $(85.4 \%)$. The respondents' registered practice was mainly concentrated in large $(49.9 \%)$ and small (31.4\%) cities. Respondents' average years of working experience was $28.4 \pm 10.2$ years. More than half of respondents participated in the CHCG (56.8\%), with an average duration of $3.5 \pm 4.6$ years. Some of the respondents reported having encountered patients with fever $(75.8 \%)$ and those with suspected COVID-19 (25.1\%) in practice. Since the COVID-19 outbreak in January 2020, nearly a quarter of the respondents had ever assisted patients with suspected COVID-19 with referral $(21.6 \%)$ or had ever sought help on the epidemic prevention hotline and health bureau for advice $(22.7 \%)$.

The 625 primary care physicians enrolled were divided into two groups: the 'willing to provide care' $(\mathrm{n}=428$, $68.5 \%)$ and 'unwilling to provide care' $(\mathrm{n}=197,31.5 \%)$ groups. Categorical variables in table 2 and continuous variables in table 3 indicate possible factors related to the respondents' willingness to provide care during the COVID-19 pandemic. Tables 2 and 3 also demonstrated factors with significant differences by $\chi^{2}$ test and t-test from univariate comparison analysis.

The results of further stepwise logistic regression analysis to determine the relative values of variables associated with willingness are shown in table 4. 'Overall perceived benefits for providing care during COVID19 ' and 'overall perceived barriers for providing care during COVID-19' were analysed and demonstrated in two different models to avoid collineation. Factors including 'participating in the CHCG' $(\mathrm{p}<0.001)$, 'knowledge about COVID-19' ( $\mathrm{p}=0.049)$, 'major specialties' $(\mathrm{p}=0.009)$, 'perceived overall benefits to providing care during COVID-19' ( $p<0.001)$, 'perceived overall barriers to providing care during COVID-19' $(\mathrm{p}<0.001)$ were independent association factors of the 'willingness to provide care.' For the suitability of the model, the $\mathrm{p}$ value of the 
Table 1 Background characteristics of the primary care physicians $(n=625)$

\begin{tabular}{lll}
\hline Items & Number & $\%$ \\
\hline Gender & & \\
Male & 534 & 85.4 \\
Female & 83 & 13.3 \\
Missing & 8 & 1.3 \\
\hline Age (years) & & \\
\hline
\end{tabular}

Average $56.6 \pm 10.6$

\begin{tabular}{lll} 
Education & & \\
University & 534 & 85.4 \\
\hline Master & 59 & 9.4 \\
\hline PhD & 22 & 3.5 \\
Others & 10 & 1.6 \\
\hline Religion & & \\
\hline Not specified & 207 & 33.1 \\
\hline Folk beliefs & 152 & 24.3 \\
\hline Buddhism & 132 & 21.1 \\
\hline Taoism & 24 & 3.8 \\
\hline Christianity & 74 & 11.8 \\
\hline Catholics & 19 & 3.0 \\
\hline Islam & 0 & 0 \\
\hline Kuan Tao & 5 & 0.8 \\
\hline Others & 12 & 1.9 \\
\hline
\end{tabular}

The importance of religion

\begin{tabular}{|lll|}
\hline Very important & 86 & 13.8 \\
\hline Important & 155 & 24.8 \\
\hline Fair & 277 & 44.3 \\
\hline Not that important & 95 & 15.1 \\
\hline Not important at all & 12 & 1.9 \\
\hline $\begin{array}{l}\text { Practice region } \\
\text { Urban }\end{array}$ & & \\
\hline Suburban & 312 & 49.9 \\
\hline $\begin{array}{l}\text { Rural area } \\
\text { Others }\end{array}$ & 196 & 31.4 \\
\hline $\begin{array}{l}\text { Specialty } \\
\text { General practitioner and family } \\
\text { medicine }\end{array}$ & 115 & 18.4 \\
\hline $\begin{array}{l}\text { Internal medicine } \\
\text { Obstetrics and gynaecology }\end{array}$ & 231 & 0.3 \\
\hline $\begin{array}{l}\text { Paediatrics } \\
\text { Otorhinolaryngologist }\end{array}$ & 71 & 37.0 \\
\hline $\begin{array}{l}\text { Surgery (surgery, ophthalmology, } \\
\text { dermatology, medical cosmetology, } \\
\text { orthopaedics) }\end{array}$ & 86 & 4.2 \\
\hline $\begin{array}{l}\text { Others (rehabilitation, neurology, } \\
\text { psychiatry) }\end{array}$ & 79 & 12.6 \\
\hline $\begin{array}{l}\text { Years of service } \\
\text { Average 28.4 } \pm 10.2\end{array}$ & 34 & 15.7 \\
\hline
\end{tabular}

Continued
Table 1 Continued

\begin{tabular}{|c|c|c|}
\hline Items & Number & $\%$ \\
\hline \multicolumn{3}{|c|}{ Participating in the Community Healthcare Group } \\
\hline Yes & 355 & 56.8 \\
\hline No & 268 & 42.9 \\
\hline \multicolumn{3}{|c|}{ Manage the following condition since January } \\
\hline Fever patient & 474 & 75.8 \\
\hline Suspected COVID-19 patient & 157 & 25.1 \\
\hline $\begin{array}{l}\text { Refer suspected COVID- } 19 \text { patient to } \\
\text { designated hospitals for further testing }\end{array}$ & 135 & 21.6 \\
\hline $\begin{array}{l}\text { Consult the central or local health } \\
\text { bureau while having difficulty with } \\
\text { referral }\end{array}$ & 142 & 22.7 \\
\hline None of the above & 123 & 19.7 \\
\hline
\end{tabular}

Hosmer-Lemeshow goodness-of-fit test were 0.847 and 0.960 .

\section{DISCUSSION}

Effective primary healthcare is important in the battle against COVID-19, and the willingness of primary care physicians to provide care during the pandemic is vital. This study identified influencing factors of willingness to provide care during COVID-19 pandemic including 'participating in the CHCG', 'physician's major specialty', 'perceived more overall benefits to providing care', 'perceived less overall barriers to providing care' and 'higher knowledge score on COVID-19'. Efforts directed at these factors are fundamental for an improved community care system in combating the COVID-19 pandemic worldwide. Furthermore, it is of high priority to strengthen the capacity of local primary care physicians, in view of the upcoming resurgence of COVID-19 cases.

Participating in the CHCG was significantly associated with the willingness of primary care physicians to provide care during the COVID-19 pandemic. Lessons from past epidemics informed the important role of primary healthcare. Strategies such as strengthening the primary healthcare system and providing coordinated with reliable information to the physicians were essential. ${ }^{18} 2930$ The innovative CHCG comprehensive primary healthcare system model was developed in Taiwan after the previous SARS outbreak and the disastrous 921 earthquake. These conditions created an awareness of the need to reinforce primary care under the tremendous public health threats. ${ }^{13}$ Under these circumstances, the physicians can provide services as a team and unite to perform group work. Taiwanese citizens who are enrolled as CHCG members for care showed a high level of satisfaction with their health consultation and received more preventive care services including influenza vaccination, which would be important in the prevention of COVID$19{ }^{13}$ Furthermore, the physicians are required to take regular education courses together, and the mandatory 
Table 2 Univariate analysis $\left(\chi^{2}\right)$ for comparing the characteristics between those willing $(n=428)$ and those unwilling $(n=197)$ to provide care

\begin{tabular}{|c|c|c|c|c|}
\hline & Willing & Not willing & & \\
\hline Variables & $\mathbf{N}(\%)$ & N (\%) & $\chi^{2}$ & $\mathrm{P}$ value \\
\hline Gender & & & 0.636 & 0.425 \\
\hline Male & $360(67.5)$ & $173(32.5)$ & & \\
\hline Female & $59(72.0)$ & $23(28.0)$ & & \\
\hline Education & & & 0.822 & 0.844 \\
\hline University & $362(68.0)$ & $170(32.0)$ & & \\
\hline Master & 43 (72.9) & $16(27.1)$ & & \\
\hline $\mathrm{PhD}$ & 14 (63.6) & $8(36.4)$ & & \\
\hline Others & 7 (70.0) & $3(30.0)$ & & \\
\hline Religion & & & 8.433 & 0.296 \\
\hline Not specified & $134(65.0)$ & $72(35.0)$ & & \\
\hline Folk beliefs & $106(69.7)$ & $46(30.3)$ & & \\
\hline Buddhism & 86 (65.6) & 45 (34.4) & & \\
\hline Taoism & $16(66.7)$ & $8(33.3)$ & & \\
\hline Christianity & $59(79.7)$ & $15(20.3)$ & & \\
\hline Catholics & $14(73.7)$ & $5(26.3)$ & & \\
\hline Islam & $0(0.0)$ & $0(0.0)$ & & \\
\hline Kuan Tao & $2(40.0)$ & $3(60.0)$ & & \\
\hline Others & $9(75.0)$ & $3(25.0)$ & & \\
\hline Practice region & & & 11.923 & $0.018^{*}$ \\
\hline Urban & 194 (62.6) & $116(37.4)$ & & \\
\hline Suburban & $145(74.0)$ & $51(26.0)$ & & \\
\hline Rural area & 75 (74.8) & $28(25.2)$ & & \\
\hline Others & $1(50.0)$ & $1(50.0)$ & & \\
\hline Specialty & & & 35.563 & $<0.001^{\star \star \star}$ \\
\hline General practitioner and family medicine & $164(71.0)$ & $67(29.0)$ & & \\
\hline Internal medicine & $46(65.7)$ & $24(34.3)$ & & \\
\hline Obstetrics and gynaecology & $15(57.7)$ & $11(42.3)$ & & \\
\hline Paediatrics & $61(78.2)$ & $17(21.8)$ & & \\
\hline Otorhinolaryngologist & $80(81.6)$ & $18(18.4)$ & & \\
\hline $\begin{array}{l}\text { Surgery (including general surgery, ophthalmology, } \\
\text { dermatology, orthopaedics) }\end{array}$ & $47(54.7)$ & $39(45.3)$ & & \\
\hline Others (including rehabilitation, neurology, psychiatry) & $13(38.2)$ & $21(61.8)$ & & \\
\hline Participating in the Community Healthcare Group & & & 22.838 & $<0.001^{\star \star \star}$ \\
\hline Yes & $269(76.2)$ & $84(23.8)$ & & \\
\hline No & $156(58.2)$ & $112(41.8)$ & & \\
\hline $\begin{array}{l}\text { Experience in managing patients with fever, suspected } \\
\text { COVID- } 19 \text { patients, referring patients for further testing, } \\
\text { consulting the central or local health bureau, since January } \\
2020\end{array}$ & & & 17.385 & $<0.001^{\star * \star}$ \\
\hline Yes & $361(72.3)$ & $138(27.7)$ & & \\
\hline No & $65(52.8)$ & $58(47.2)$ & & \\
\hline
\end{tabular}

courses for the physicians in the CHCG include topics on infection control. This would provide the physicians with confidence and ability to care for patients with COVID-19 during the pandemic. The design and successful implementation of FPICP and CHCG might be the reasons why the physicians participating in the CHCG are more 
Table 3 Univariate analysis (t-test) for comparing the characteristics between those willing $(n=428)$ and those unwilling $(n=197)$ to provide care

\begin{tabular}{|c|c|c|c|c|}
\hline \multirow[b]{2}{*}{ Variables } & Willing & Not willing & \multirow[b]{2}{*}{$\mathbf{T}$} & \multirow[b]{2}{*}{$P$ value } \\
\hline & Mean (SD) & Mean (SD) & & \\
\hline Age (years) & $56.8(9.3)$ & $56.2(9.3)$ & -0.6 & 0.519 \\
\hline Years of participating in the Community Healthcare Group & $4.0(4.6)$ & $2.6(4.1)$ & -3.6 & $<0.001 \dagger$ \\
\hline Knowledge about COVID-19 & $14.9(2.1)$ & $14.4(2.2)$ & -2.9 & $0.004^{*}$ \\
\hline Overall perceived barriers for providing care during COVID-19 & $3.8(1.9)$ & $4.4(2.1)$ & 3.1 & $0.002^{\star}$ \\
\hline
\end{tabular}

${ }^{*} \mathrm{P}<0.01$.

$+\mathrm{P}<0.001$.

willing to provide care during the COVID-19 pandemic. The promotion of this type of primary healthcare model reinforces infection control in the communities and could be helpful in the prevention of the persistent COVID-19 pandemic.

Physician's major specialties was an association factor to the willingness of providing care, and specialties as family physician or general practitioners had higher willingness to provide care than the specialty of rehabilitation, neurology and psychiatry. This result might be due to the familiarity of these practitioners with undetermined number of conditions compared with those of specialists who may be in fear or withdraw when faced with an uncertain acute illness. The clinical experiences of family physicians and general practitioners, which include diagnosing and management of flu-like fever symptoms, are important in the monitoring of viral illnesses in the community. Previous studies also revealed the willingness of general practitioners to provide care during the influenza pandemic when provided with adequate supply of personal protective equipment, and appropriate education and training. ${ }^{31-34}$ For a sustainable model, the added on task of patients with COVID-19 without overcrowding the original medical care facilities, would require the recruitment of family physicians and general practitioners who are willing to provide care in all healthcare systems worldwide. Moreover, in future, medical education and training need to put more emphasis on the adequate supply of the health workforce in these specialties including those with more experience of managing acute infectious illnesses.

The finding that physicians who perceived more threat, more stress and who had lower knowledge scores on COVID-19 were less willing to provide care during the pandemic has important implications for policy makers. Infectious diseases pose threats to frontline healthcare professionals combating these diseases. A review that examined the psychological impact on healthcare professionals facing novel viral outbreaks revealed that staff in contact with affected patients had greater levels of both acute and post-traumatic stress in comparison with controls. Risk factors for psychological distress include being younger, being more junior, being the parents of dependent children or having an infected family member. Longer quarantine, lack of practical support and stigma also contributed to the distress in this review. ${ }^{21}$ To understand the impact of the COVID-19 pandemic on the mental health status of healthcare professionals, a Spanish study concluded that anxiety and depression are the most common symptoms among healthcare professionals. Insomnia, extreme fatigue, emotional exhaustion and physical symptoms are also often reported. ${ }^{35}$ Another study in China revealed that among healthcare professionals, those in the Wuhan area scored significantly higher than those outside Wuhan on several items in the Psychological Stress Questionnaire, including the thought of being in danger, worrying about self-illness and family infection, lack of psychological guidance and poor sleep quality. ${ }^{36}$ As the results of this study suggest, it is important for governments, worldwide, to provide psychological interventions to mitigate the threats and stress experienced by primary care physicians. Moreover, training sessions for primary healthcare staff to increase their level of knowledge about COVID-19 are necessary to enhance their willingness to provide care to COVID-19 patients.

There are several limitations to this study. First, the response rate was moderate $(62.5 \%)$. This response rate might have been affected by the heavy workload of the primary care physicians during the COVID-19 pandemic, as well as the large volume of questionnaires that they might have received. Nonetheless, the response of the participants, nationwide, still provides important information for the governments and the healthcare system. Second, the healthcare system infrastructure and the health insurance reimbursement in Taiwan are unique; thus, these could limit the application of the results to other countries. However, the experiences learnt from this study are paramount for the reform of primary healthcare systems that are confronted both by COVID-19 and other infectious disease pandemics. Third, differences in the level of strategies by governments to control the surge of COVID-19 and vaccinations may also impact the generalisability of the results. Fourth, even though this study is 
Table 4 Logistic regression analysis results showing factors correlated with the willingness to provide care during COVID-19

$\begin{array}{llllll}\text { Variables } & \text { B } & \text { SE } & \text { OR } & 95 \% \mathrm{Cl} & \text { P value }\end{array}$

Model 1

Participating in the Community Healthcare Group

\begin{tabular}{|c|c|c|c|c|c|}
\hline Yes & 0.689 & 0.195 & 1.991 & 1.359 to 2.917 & $<0.001 \neq$ \\
\hline No & & & 1.000 (ref) & & \\
\hline Knowledge about COVID-19§ & 0.094 & 0.048 & 1.098 & 1.000 to 1.206 & $0.049^{*}$ \\
\hline Specialty & & & & & $0.009 \dagger$ \\
\hline General practitioner and family medicine & & & 1.000 (ref) & & \\
\hline Internal medicine & -0.276 & 0.307 & 0.759 & 0.416 to 1.385 & 0.369 \\
\hline OBGYN & -0.511 & 0.441 & 0.600 & 0.253 to 1.425 & 0.247 \\
\hline Paediatrics & 0.401 & 0.328 & 1.493 & 0.786 to 2.838 & 0.221 \\
\hline ENT & 0.580 & 0.319 & 1.787 & 0.957 to 3.336 & 0.068 \\
\hline $\begin{array}{l}\text { Surgery (surgery, ophthalmology, } \\
\text { dermatology, medical cosmetology, } \\
\text { orthopaedics) }\end{array}$ & -0.333 & 0.293 & 0.717 & 0.404 to 1.271 & 0.254 \\
\hline $\begin{array}{l}\text { Others (rehabilitation, neurology, } \\
\text { psychiatry) }\end{array}$ & -0.993 & 0.405 & 0.370 & 0.168 to 0.819 & $0.014^{*}$ \\
\hline Practice region & & & & & 0.104 \\
\hline Urban & & & 1.000 (ref) & & \\
\hline Suburban & 0.460 & 0.216 & 1.584 & 1.037 to 2.420 & $0.033^{*}$ \\
\hline Rural area & 0.493 & 0.272 & 1.637 & 0.960 to 2.792 & 0.070 \\
\hline Others & 0.021 & 1.506 & 1.021 & 0.053 to 19.543 & 0.989 \\
\hline $\begin{array}{l}\text { Overall perceived benefits for providing care } \\
\text { during COVID-19§ }\end{array}$ & 0.173 & 0.047 & 1.189 & 1.083 to 1.304 & $<0.001 \ddagger$ \\
\hline Hosmer and Lemeshow test & & & & & 0.847 \\
\hline \multicolumn{6}{|l|}{ Model 2} \\
\hline \multicolumn{6}{|l|}{ Participating in the Community Healthcare Group } \\
\hline Yes & 0.696 & 0.195 & 2.005 & 1.368 to 2.937 & $<0.001 \neq$ \\
\hline No & & & 1.000 (ref) & & \\
\hline Knowledge about COVID-19 & 0.094 & 0.048 & 1.099 & 1.001 to 1.207 & $0.049^{*}$ \\
\hline Specialty & & & & & $0.009 \dagger$ \\
\hline General practitioner and family medicine & & & 1.000 (ref) & & \\
\hline Internal medicine & -0.275 & 0.307 & 0.760 & 0.416 to 1.386 & 0.370 \\
\hline OBGYN & -0.507 & 0.442 & 0.602 & 0.253 to 1.431 & 0.251 \\
\hline Paediatrics & 0.404 & 0.328 & 1.498 & 0.788 to 2.847 & 0.218 \\
\hline ENT & 0.577 & 0.318 & 1.781 & 0.954 to 3.324 & 0.070 \\
\hline $\begin{array}{l}\text { Surgery (surgery, ophthalmology, } \\
\text { dermatology, medical cosmetology, } \\
\text { orthopaedics) }\end{array}$ & -0.329 & 0.293 & 0.720 & 0.406 to 1.277 & 0.261 \\
\hline $\begin{array}{l}\text { Others (rehabilitation, neurology, } \\
\text { psychiatry) }\end{array}$ & -0.990 & 0.405 & 0.372 & 0.168 to 0.822 & $0.014^{*}$ \\
\hline Practice region & & & & & 0.108 \\
\hline Urban & & & 1.000 (ref) & & \\
\hline Suburban & 0.462 & 0.216 & 1.587 & 1.039 to 2.425 & $0.033^{*}$ \\
\hline Rural area & 0.482 & 0.273 & 1.620 & 0.949 to 2.764 & 0.077 \\
\hline Others & 0.023 & 1.508 & 1.024 & 0.053 to 19.651 & 0.988 \\
\hline $\begin{array}{l}\text { Overall perceived barriers for providing care } \\
\text { during COVID-19§}\end{array}$ & -0.174 & 0.048 & 0.840 & 0.766 to 0.923 & $<0.001 \ddagger$ \\
\hline
\end{tabular}

Continued 
Table 4 Continued

\begin{tabular}{|c|c|c|c|c|c|}
\hline Variables & B & SE & OR & $95 \% \mathrm{Cl}$ & $P$ value \\
\hline
\end{tabular}

${ }^{*} \mathrm{P}<0.05$.

$\dagger \mathrm{P}<0.01$.

$\pm \mathrm{P}<0.001$.

$\S$ These variables were scores as continuous variables in the model.

$\mathrm{B}$, coefficients; ENT, ear nose and throat; OBBGYN, obstetrics and gynaecology.;

a nationwide survey, the willingness to provide care may be affected by differences in the cultural backgrounds and values of physicians towards physicians' professionalism. These findings may require modifications when applied to other countries. In addition, Cronbach's alpha of 'knowledge about COVID-19' measure was only $0.5-0.6$. However, the questionnaire was designed by five primary care physicians and two infection specialists with careful scrutiny of the literature available in the beginning of the epidemic. Because the COVID-19 was started from an unknown SARS-CoV-2 pathogen, there were still many pathways, transmission or prevention needed to be studied.

Enhancing the willingness of primary care physicians to provide care during the COVID-19 pandemic is essential in optimising sustainable healthcare. Building a comprehensive primary care system, such as Taiwan's FPICP with CHCG, training of more healthcare professionals especially family physicians or general practitioners, implementing psychological intervention and providing educational courses for primary care physicians by the medical associations or the governments worldwide, would effectively strengthen the community care workforce. The experiences learnt are informative globally to build a strong coordinated healthcare system to combat the persistent and unprecedented COVID-19 pandemic.

Correction notice The article has been corrected since it first published. 3rd affiliation corrected to: Brian's Family Doctor Clinic, New Taipei City, Taiwan. Word "reparation" has been corrected to "preparation" in acknowledgement section. And twitter handle for Brian Bih-Jeng Chang's has been added.

Twitter Chyi-Feng Jeff Jan @youthDr36 and Brian Bih-Jeng Chang @ BrianChang0808

Acknowledgements The authors would like to gratefully acknowledge all the members of the COVID-19 working group of the Taiwan Medical Association for their useful opinions. We also thank Ms Yen-Chun Lin and Ms Po- Shan Chien for the preparation of this manuscript.

Contributors H-LH conceptualised the topic of the paper, conducted the analysis and wrote the manuscript. C-FJJ and BB-JC conceptualised the topic of the paper and participated in the data collection. T-YC was the principal investigator for the project, conceptualised the topic, participated in data collection, conducted the analysis and wrote the manuscript. All authors read and approved the final manuscript.

Funding This study was supported by the Taiwan Medical Association (award/ grant number: $\mathrm{N} / \mathrm{A}$ ).

Competing interests None declared.

Patient consent for publication Not required.
Ethics approval The Medical Policy Committee of Taiwan Medical Association approved the study protocol. The document had no number/ID but was attached as the supplement file with the title 'TMA Certified IRB exemption Documents_2020'.

Provenance and peer review Not commissioned; externally peer reviewed.

Data availability statement Data are available upon reasonable request.

Supplemental material This content has been supplied by the author(s). It has not been vetted by BMJ Publishing Group Limited (BMJ) and may not have been peer-reviewed. Any opinions or recommendations discussed are solely those of the author(s) and are not endorsed by BMJ. BMJ disclaims all liability and responsibility arising from any reliance placed on the content. Where the content includes any translated material, BMJ does not warrant the accuracy and reliability of the translations (including but not limited to local regulations, clinical guidelines, terminology, drug names and drug dosages), and is not responsible for any error and/or omissions arising from translation and adaptation or otherwise.

Open access This is an open access article distributed in accordance with the Creative Commons Attribution Non Commercial (CC BY-NC 4.0) license, which permits others to distribute, remix, adapt, build upon this work non-commercially, and license their derivative works on different terms, provided the original work is properly cited, appropriate credit is given, any changes made indicated, and the use is non-commercial. See: http://creativecommons.org/licenses/by-nc/4.0/.

\section{ORCID iDs}

Hsien-Liang Huang http://orcid.org/0000-0002-2163-5596

Chyi-Feng Jeff Jan http://orcid.org/0000-0003-2893-2187

Tai-Yuan Chiu http://orcid.org/0000-0002-8528-7981

\section{REFERENCES}

1 Adebowale V, Alderson D, Burn W, et al. Covid-19: Call for a rapid forward looking review of the UK's preparedness for a second wave - an open letter to the leaders of all UK political parties. BMJ 2020;369:m2514.

2 Xu S, Li Y. Beware of the second wave of COVID-19. The Lancet 2020;395:1321-2.

3 Organization WH. WHO coronavirus disease (COVID-19) dashboard $2020 \mathrm{https}$ ://covid19. who. int/?adgroupsurvey=\{adgroupsurvey $\} \&$ gclid=CjwKCAjwt8uGBhBAEiwAayu 9SeyB0SiBCUdWMI iaxyIShvhYQu_xCFIn3qe-PM12FTOw-5TEknpRoCeUMQAvD_BwE

4 Kissler SM, Tedijanto C, Goldstein E, et al. Projecting the transmission dynamics of SARS-CoV-2 through the postpandemic period. Science 2020;368:860-8.

5 Vogel L. Is Canada ready for the second wave of COVID-19? Can Med Assoc J 2020;192:E664-5.

6 Roehr B. Covid-19 is threatening the survival of US primary care. BMJ 2020;369:m2333.

7 Lotta G, Wenham C, Nunes J, et al. Community health workers reveal COVID-19 disaster in Brazil. Lancet 2020;396:365-6.

8 Marshall M, Howe A, Howsam G, et al. COVID-19: a danger and an opportunity for the future of general practice. $\mathrm{Br} J$ Gen Pract 2020;70:270-1.

9 Finn SD. COVID-19-Back to the future. JAMA Intern Med 2020;180:1149-50.

10 Greenhalgh T, Koh GCH, Car J. Covid-19: a remote assessment in primary care. BMJ 2020;368:m1182.

11 Wang CJ, Ng CY, Brook RH. Response to COVID-19 in Taiwan: big data analytics, new technology, and proactive testing. JAMA 2020;323:1341-2. 
12 Cheng S-Y, Wang CJ, Shen AC-T, et al. How to safely Reopen colleges and universities during COVID-19: experiences from Taiwan. Ann Intern Med 2020;173:638-41.

13 Jan C-F, Chiu T-Y, Chen C-Y, et al. A 10-year review of health care reform on family practice integrated care Project-Taiwan experience. Fam Pract 2018;35:352-7.

14 Chen K-T, Twu S-J, Chang H-L, et al. Sars in Taiwan: an overview and lessons learned. International Journal of Infectious Diseases 2005;9:77-85.

15 Rauh AL, Linder JA. Covid-19 care before, during, and beyond the hospital. BMJ 2020;369:m2035.

16 Barnes M, Sax PE. Challenges of "Return to Work" in an ongoing pandemic. N Engl J Med 2020;383:779-86.

17 Lang T. Plug COVID-19 research gaps in detection, prevention and care. Nature 2020;583:333.

18 Desborough J, Dykgraaf SH, Phillips C, et al. Lessons for the global primary care response to COVID-19: a rapid review of evidence from past epidemics. Fam Pract 2021;7.

19 Remuzzi A, Remuzzi G. COVID-19 and Italy: what next? The Lancet 2020;395:1225-8.

20 Tan Z, Khoo DWS, Zeng LA, et al. Protecting health care workers in the front line: innovation in COVID-19 pandemic. J Glob Health 2020;10:010357.

21 Kisely S, Warren N, McMahon L, et al. Occurrence, prevention, and management of the psychological effects of emerging virus outbreaks on healthcare workers: rapid review and meta-analysis. BMJ 2020;369:m1642.

22 McConnell D. Balancing the duty to treat with the duty to family in the context of the COVID-19 pandemic. J Med Ethics 2020;46:360-3

23 Gan X, Shi Z, Chair SY, et al. Willingness of Chinese nurses to practice in Hubei combating the coronavirus disease 2019 epidemic: a cross-sectional study. J Adv Nurs 2020.

24 Ehrenstein BP, Hanses F, Salzberger B. Influenza pandemic and professional duty: family or patients first? A survey of hospital employees. BMC Public Health 2006;6:311.
25 Damery S, Wilson S, Draper H, et al. Will the NHS continue to function in an influenza pandemic? A survey of healthcare workers in the West Midlands, UK. BMC Public Health 2009;9:142.

26 Shi Y, Wang J, Yang Y, et al. Knowledge and attitudes of medical staff in Chinese psychiatric hospitals regarding COVID-19. Brain Behav Immun Health 2020;4:100064.

27 Cook DA, Beckman TJ. Current concepts in validity and reliability for psychometric instruments: theory and application. Am J Med 2006;119:166.e7-166.e16.

28 Polit DF, Beck CT. The content validity index: Are you sure you know what's being reported? critique and recommendations. Res Nurs Health 2006;29:489-97.

29 Wong WCW, Lee A, Tsang KK, et al. How did general practitioners protect themselves, their family, and staff during the SARS epidemic in Hong Kong? J Epidemiol Community Health 2004;58:180-5.

30 Wong WCW, Wong SYS, Lee A, et al. How to provide an effective primary health care in fighting against severe acute respiratory syndrome: the experiences of two cities. Am J Infect Control 2007;35:50-5.

31 Shaw KA, Chilcott A, Hansen E. The GP's response to pandemic influenza: a qualitative study. Fam Pract 2006;23:267-72.

32 Lee A, Chuh AAT. Facing the threat of influenza pandemic - roles of and implications to general practitioners. BMC Public Health 2010;10:661.

33 Hogg W, Huston P, Martin C, et al. Enhancing public health response to respiratory epidemics: are family physicians ready and willing to help? Can Fam Physician 2006;52:1254-60.

34 Wong SYS, Kung K, Wong MCS, et al. Primary care physicians' response to pandemic influenza in Hong Kong: a mixed quantitative and qualitative study. Int $J$ of Dis 2012;16:e687-91.

35 Serafini G, Parmigiani B, Amerio A, et al. The psychological impact of COVID-19 on the mental health in the general population. QJM 2020;113:531-7. doi:10.1093/qjmed/hcaa201

36 Wu W, Zhang Y, Wang P, et al. Psychological stress of medical staffs during outbreak of COVID-19 and adjustment strategy. J Med Virol 2020;92:1962-70. 